\title{
OBITUARY
}

\section{In memory of George Papageorgiou, the father of biophysics of photosynthesis in Greece}

\section{TSIMILLI-MICHAEL}

\author{
3 Ath. Phylactou, Nicosia CY-1100, Cyprus \\ e-mail: tsimicha@spidernet.com.cy
}

Dr. George Papageorgiou, former Research Director of the Laboratory of Membrane Biophysics and Biotechnology at the National Centre for Scientific Research 'Demokritos', Athens, Greece, passed away on November 21, 2020.

George Papageorgiou was the father of biophysics of photosynthesis in Greece. His contribution to the science of photosynthesis for more than 50 years has been greatly acknowledged worldwide.

During September 21-26, 2015, an international conference 'Photosynthesis Research for Sustainability 2015' was held in his honour in Crete (Kolymvari, Chania). I am grateful to Dr. Kostas Stamatakis, who has collaborated with George for many years, for his initiative and hard work to organise that conference, where people from the photosynthesis society had the opportunity to express their deep respect to George.

The 'Letter to the Editor - Honoring George C. Papageorgiou' by Stamatakis et al. (2016) provides the opportunity for the readers to understand and admire the high impact of Papageorgiou in photosynthesis research. It stands also for what one could write in a 'classic' obituary, and I am grateful that Photosynthetica published it when Papageorgiou was alive and could thus appreciate it.

So, rather than an obituary, I would like to repeat here what I had said in my presentation at that conference in 2015 and, later, in an opinion paper published in Photosynthetica, which was 'Dedicated to George $C$. Papageorgiou, who has been serving for more than 50 years the science and education of photosynthesis with integrity and devotion' (Tsimilli-Michael and Haldimann 2017):

Dr. George C. Papageorgiou is a well known and highly respected scientist, who has significantly contributed to the advancement of our understanding of photosynthesis for more than 50 years and was a pioneer in establishing and advancing photosynthesis research in Greece. What is probably less known is that he has been also an outstanding and passionate teacher and mentor, who has guided his students to attain the essence of knowledge, a deep understanding of the fundamentals. Without considering anything as obvious, he was explaining with patience both theoretical and experimental aspects, working with

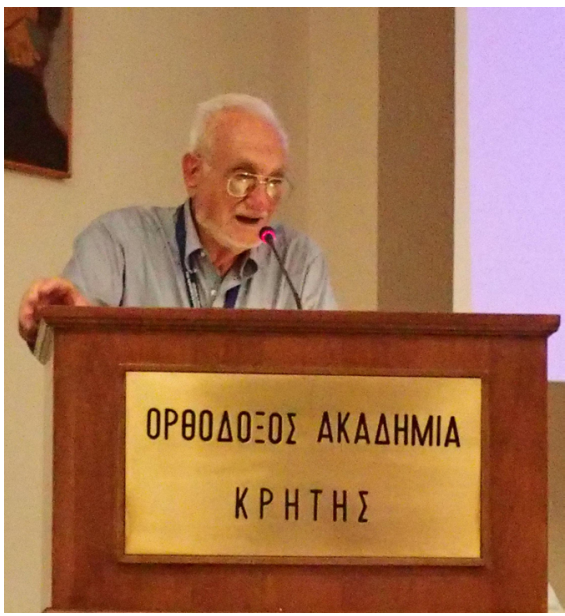

George C. Papageorgiou. Photo by Toshiyuki Shinoda, provided by Kostas Stamatakis.

them side by side at the bench and with the fluorimeter, teaching them how to write publications, motivating, inspiring, and fascinating them, triggering thus the best in them. His many publications reflect, with their remarkable quality and clarity, not only his scientific but also his teaching capabilities driven by his strong dedication in educating not only his students but also the readers of his publications.

I had the privilege, as his postgraduate student in the early 1970s, to experience at first hand these virtues, appreciate and benefit from them, and I am happy for the opportunity to acknowledge this publicly, honour him and express my gratitude for the inspiration that holds for life.

\section{References}

Stamatakis K., Allakhverdiev S.I., Garab G., Govindjee: Honoring George C. Papageorgiou. - Photosynthetica 54: 158-160, 2016.

Tsimilli-Michael M., Haldimann P.: Sustainability of photosynthesis research - when research is impeded by the cults of audit and management. - Photosynthetica 55: 391-400, 2017.

(C) The authors. This is an open access article distributed under the terms of the Creative Commons BY-NC-ND Licence. 